\title{
Special Phenomena in Boiling
}

\author{
Dr. Cees W.M. van der Geld ${ }^{1}$ \\ ${ }^{1}$ Faculty of Chemical Engineering and Chemistry, Eindhoven University of Technology \\ Groene Loper 5, 5612 AE Eindhoven, The Netherlands
}

\section{Extended Abstract}

Nucleate boiling is one of the most efficient modes of heat transfer, yet many aspects of nucleate boiling are not well understood even today. Special aspects of boiling occur when

- liquid is in contact with solid plates at temperatures exceeding the critical temperature

- a boiling bubble grows isotropic and fast

- other nucleation sites occur upstream.

This presentation aims to highlight some unexpected experimental findings and to attempt physical explanations of them.

Quench cooling in the steel industry has been studied extensively but progress is generally hampered by the inaccessibility of the process. We have applied a borescope with an observation path right through an impinging water jet to experimentally reveal boiling phenomena that were not observed before.

The first striking phenomenon is the occurrence of air bubbles floating on top of a vapor layer. The air bubbles are freed from the impinging water by effervescence [1] and their size and number depend on the amount of air dissolved in the water of the jet.

Wetting of plates was found to occur at temperatures exceeding the thermodynamic limit for water superheat. Highfrequency observations via the borescope have revealed that contact at such temperatures does occur, but only intermittently and as a highly transient process. A cyclic occurrence of explosive boiling and condensation happens. The duration of a flashing cycle is roughly proportional to the area of the flashing patch [2].

The main forces acting on the center of mass of a growing boiling bubble are given by capillary action and by the overpressure inside the bubble. Their difference is finely tuned by shape deformation and compensates gravity and other forces during bubble growth. In a laboratory experiment with a dedicated set-up it has been shown that the added mass force may play an essential role in boiling bubble detachment and explains detachment against gravity [3].

Nucleation site interactions have been studied in a flow boiling setup [4,5]. The added convective heat of an upstream generator is may promote bubble nucleation at a downstream site or may cause deactivation of bubble nucleation there. When a bubble nucleates as another vapor bubble passes by, the nucleating bubble will force a jet of liquid through the middle of the approaching bubble.

\section{References}

[1] H. Leocadio, C. W. M. van der Geld and J. C. Passos. "Rewetting and boiling in jet impingement on high temperature steel surface", Physics of Fluids, 30(12):122102, 2018.

[2] C.F. Gomez, C.W.M. van der Geld, J.G.M. Kuerten, R. Liew, M. Bsibsi and B.P.M. van Esch, "The nature of boiling during rewetting of surfaces at temperatures exceeding the thermodynamic limit for water superheat", J. of Fluid Mechanics, 895:1-20, 2020.

[3] C.W.M. van der Geld, C.H.M. Baltis \& G.J.M. Priems, "Forces on rapidly growing vapor bubbles on a wall in forced convection with varying angle of inclination”, Colloids and Surfaces A: Physicochemical and Engineering Aspects, 505, 29-36, 2016.

[4] C.H.M. Baltis, "Nucleate boiling bubble mechanics in forced convection", Ph.D. dissertation, Eindhoven Univ. of Technology, 2014.

[5] C. H.M. Baltis and C. W.M. van der Geld, "Heat transfer mechanisms of a vapour bubble growing at a wall in saturated upward flow", J. of Fluid Mechanics, 771:264-302, 2015. 